\title{
EMPREENDEDORISMO FEMININO: TECENDO A TRAMA DE DEMANDAS CONFLITANTES
}

\author{
Eva G. Jonathan \\ Taissa M. R. da Silva
}

Pontifícia Universidade Católica do Rio de Janeiro, Rio de Janeiro, Brasil

RESUMO: Face à multiplicidade dos papéis femininos, este artigo se propõe a discutir as demandas conflitantes vivenciadas por mulheres empreendedoras e as estratégias que elas utilizam para enfrentá-las. A análise do discurso de entrevistas feitas com donas de negócios próprios revela a existência de três categorias de situações conflituosas: conflitos no espaço do trabalho; conflitos entre demandas familiares e profissionais; conflitos entre demandas do trabalho e pessoais. Para fazer frente às demandas conflitantes, as empreendedoras recorrem principalmente às seguintes estratégias: auto-organização do tempo, estabelecimento de parcerias e cumplicidade, e uso de dispositivos de alívio de tensão. À luz da literatura sobre empreendedorismo feminino, os dados indicam que as empreendedoras inovam no confronto dos impasses, introduzindo transformações nos contextos familiar, profissional e pessoal.

PALAVRAS-CHAVE: empreendedorismo feminino; conflito família-trabalho; gênero e trabalho.

\section{WOMEN'S ENTREPRENEURSHIP: \\ WEAVING THE WEB OF CONFLICTING DEMANDS}

ABSTRACT: In the face of multiple gender roles, this article aims to discuss the conflicting demands experienced by women entrepreneurs and the strategies they use to cope with them. Content analysis of interviews carried out with women business owners reveals three categories of conflicting situations: conflicts at work; family-work conflicts; conflicts between work and personal demands. The main strategies these women use in order to oppose the conflicting situations are: self-organization of time; establishment of partnerships and complicity; and stress alleviation mechanisms. In the light of gender entrepreneurship literature, data indicates that women entrepreneurs innovate when confronting with dilemmas, introducing changes in the professional, family and personal context.

KEYWORDS: women's entrepreneurship; work-family conflict; gender and work.

\section{Introdução}

$\mathrm{Na}$ atualidade, várias contingências cercam a inserção das mulheres no espaço público do trabalho e, em todo o mundo, cresce o interesse pela análise das características e conseqüências do trabalho feminino. Neste sentido, este artigo pretende provocar discussões e reflexões sobre uma forma específica de inserção das mulheres no mundo do trabalho constituída pelo empreendedorismo feminino.

Segundo Hisrich \& Peters (2002), o empreendedorismo se caracteriza por uma capacidade de identificar oportunidades e criar algo inovador sob condições de incerteza, assumindo os riscos aí envolvidos. Persistência e visão de futuro envolvem o processo de empreender que tem como resultantes uma nova maneira de realizar um trabalho um novo produto, serviço ou atividade - ou a criação de um novo empreendimento. Tal concepção, aqui adotada para analisar o empreendedorismo feminino no Brasil, deixa evidente que variados fatores psicológicos, tais como motivação, atitudes e comportamentos estão envolvidos na noção de empreendedorismo, como mostraram os estudos pioneiros de McClelland (1961).

A análise do empreendedorismo feminino tem despertado a atenção de investigadores, como Moore \& Buttner (1997), que examinam diversas características psicológi- cas e sociais das empreendedoras. Busca-se mapear as experiências de mulheres que, ao criarem e/ou assumirem a liderança de seus próprios negócios, inovam, transpondo o denominado "teto de vidro", entendido como uma barreira simbólica que dificulta a ascensão das mulheres aos níveis mais altos da administração empresarial (Morrison, White \& Van Velsor, 1987). No Brasil, as empreendedoras inovam também na cultura organizacional, ao se colocarem como um contraponto à exclusão das mulheres do processo sucessório de empresas familiares, fato observado por Macêdo, Caixeta, Guimarães, Macedo \& Hernandez (2004).

A questão da criação e condução de firmas por mulheres brasileiras possui grande relevância social e econômica no âmbito das micro, pequenas e médias empresas, pois é neste contexto que se concentram os empreendedores brasileiros dos quais $46 \%$ são mulheres, somando a expressiva cifra de 6,4 milhões de empreendedoras (Global Entrepreneurship Monitor [GEM], 2003). A atividade das empreendedoras brasileiras se insere no significativo potencial econômico do empreendedorismo feminino praticado na América Latina e no Caribe (Weeks \& Seiler, 2001). Estas autoras verificam que as empreendedoras destas regiões compartilham muitas características com outras mu- 
lheres empreendedoras. Independentemente da nacionalidade, são semelhantes, por exemplo, os tipos de negócios mantidos, bem como as modalidades de desafios e as questões enfrentadas pelas empreendedoras para fazer seus negócios crescerem.

No entanto, são escassas as pesquisas mais aprofundadas sobre o empreendedorismo feminino no Brasil. Busca-se, então, com uma abordagem psicossocial da questão, contribuir para a construção do conhecimento nesta área. Neste sentido, o objetivo específico deste artigo é analisar os impasses vivenciados pelas empreendedoras brasileiras e as formas de ação que utilizam para lidar com as demandas profissionais, familiares e pessoais.

\section{Multiplicidade de papéis e a articulação Família-Trabalho-Pessoa}

Mizrahi (2004), ao analisar a interface entre o mundo da família e o do trabalho, tece pertinentes críticas às exigências da produção e à ausência de questionamento acerca da organização do trabalho, afirmando que sua atual estrutura tem reflexos negativos na relação pais e filhos, bem como na vida familiar como um todo.

Por sua vez, Barnett (2004) argumenta que tanto a organização do trabalho quanto a da família repousam em mitos, ainda hoje existentes, relativos à diferença entre os gêneros. A idéia de que as mulheres têm necessidades, inclinações e capacidades para cuidar e se ocupar do lar, ao passo que os homens têm habilidades para atividades fora do lar e para prover, cria uma armadilha. Homens e mulheres se tornam prisioneiros de expectativas e comportamentos vinculados a ideais em relação a quem trabalha ("trabalhador ideal") e a quem cuida do lar ("dona de casa ideal").

A questão gera barreiras e desvantagens que atingem especialmente as mulheres que são mães e que trabalham. Em relação a elas, há dois estereótipos que prevalecem: ou são percebidas como calorosas e pouco competentes, não merecendo novas oportunidades de emprego, de promoção ou de educação adicional, ou, ao contrário, são vistas como competentes e frias (Cuddy, Fiske \& Glick, 2004). A representação social da maternidade se constitui, portanto, em um imenso muro que dificulta o trânsito das mulheres no espaço público e reforça as imagens idealizadas acima discutidas.

Assim, tradicionalmente, as mulheres têm se dedicado às atividades no espaço privado e seu ingresso no mercado de trabalho não implicou na supressão destas atividades. Um forte envolvimento em atividades produtivas fora do lar, bem como a dedicação e a participação ativa na administração da casa e nos cuidados com a família, faz parte da vida das mulheres contemporâneas. A chamada "dupla jornada", que remete ao acúmulo de tarefas - públicas e privadas -, constitui a origem de conflitos, problemas e desgastes (Jablonski, 1996; Rocha-Coutinho, 2003).
No entanto, pode-se argumentar que a multiplicidade de papéis femininos não envolve demandas incompatíveis em sua natureza, sendo necessário reconhecer que os papéis de gênero são construídos socialmente e que os processos de socialização demarcam espaços, expectativas, e atividades a serem desempenhadas pelos membros da sociedade. É neste contexto de construção social do sujeito que emerge e circula a percepção do inconciliável, do "ou isso ou aquilo", e o discurso da culpa feminina, internalizada pelas mulheres no processo de socialização. Nesta abordagem da condição feminina, não há saída para a mulher contemporânea: culpada por trabalhar; culpada por não o fazer.

A questão ganha complexidade na medida em que mulheres, e especificamente mães, que trabalham apresentam melhores índices de bem-estar e de satisfação do que aquelas que não trabalham (Cherlin, 2001; Vandewater, Ostrove \& Stewart,1997). Tais dados sugerem a necessidade de modificar o pensamento em relação ao trabalho feminino, de questionar o tabu do fardo que o trabalho fora do lar representa para as mulheres. Como observa Cherlin, uma vida que contempla trabalho e maternagem traz satisfação e sentimento de realização à protagonista. Dessa forma, o desempenho de múltiplos papéis contribui para o aumento das fontes de satisfação (Possati \& Dias, 2002), e, portanto, transitar simultaneamente nos espaços públicos e privados pode se constituir como um fator enriquecedor e, não, de estresse e culpa.

Por outro lado, embora muitos observadores do comportamento feminino atribuam às mulheres uma aptidão para pensar e fazer diversas coisas simultaneamente e considerem a multiplicidade de papéis uma característica do universo feminino, faz-se necessário ganhar uma melhor compreensão acerca das formas utilizadas pelas mulheres para lidar com tal multiplicidade. Neste sentido, segundo Uchitelle (2002), as mulheres têm encontrado um meio termo entre trabalho e família.

Por sua vez, Tiedge (2004) mostra que mães que trabalham freqüentemente utilizam cinco estratégias para enfrentar as tensões entre as demandas do trabalho e as da maternagem. São elas: (a) estratégia super-mulher, que envolve buscar atingir com eficiência todas as expectativas vinculadas aos diferentes papéis sociais; (b) planejamento e administração do tempo, que implica em otimizar o desempenho dos papéis; (c) reinterpretação cognitiva das demandas, envolvendo, por exemplo, diminuir seu próprio padrão de exigências; (d) afastamento de atividades menos importantes, que pode incluir não assumir novas responsabilidades; (e) estratégia multitarefa, que envolve desempenhar várias atividades ao mesmo tempo. Confirmando Cherlin (2001), a autora observa que as próprias mulheres percebem consequiências positivas decorrentes do envolvimento em múltiplos papéis, ao mesmo tempo 
que enfatizam que as estratégias que adotam são constantemente aperfeiçoadas em função da experiência adquirida.

As análises realizadas com a crescente população de mulheres que exercem funções de liderança nas empresas contribui para enriquecer a compreensão da articulação entre o espaços público e privado. Neste sentido, segundo Rocha-Coutinho (2003), executivas cariocas de classe média possuem o ideal de conciliar as necessidades familiares, profissionais e pessoais. Visando concretizar tal ideal, diversas estratégias são adotadas conscientemente, tais como: o estabelecimento da regra de não levar trabalho para casa; a adoção de expedientes que garantam um tempo pessoal, como, por exemplo, o de reduzir a jornada de trabalho; o expediente de buscar harmonizar os compromissos de todos os membros da família, assegurando um tempo de convivência; ou, ainda, a delegação de tarefas a todos os familiares, estabelecendo verdadeiras parcerias na condução da casa.

Em relação às empreendedoras, pesquisas têm demonstrado que elas buscam auto-realização pessoal através da criação e do comando de seus próprios negócios (Jonathan, 2001; Moore \& Buttner, 1997). Verifica-se, também, que estratégias desenvolvidas por empreendedoras com filhos adolescentes são eficazes tanto para satisfazer suas próprias emoções quanto para satisfazer as necessidades de seus filhos (Shindhutte, Morris \& Brennan, 2001), sinalizando a conciliação das demandas profissionais, familiares e pessoais.

No contexto brasileiro, Jonathan (2001) observa que as empreendedoras almejam intensamente estabelecer um ponto de equilíbrio entre as demandas profissionais e familiares e parecem alcançar tal equilíbrio na medida em que percebem e afirmam que trabalho e família se ajudam e se beneficiam mutuamente. Por outro lado, trabalho, filhos e respeito próprio se constituem como fontes de altos e semelhantes índices de satisfação das empreendedoras brasileiras, indicando que os espaços profissional, familiar e pessoal contribuem de maneira equilibrada para o bem-estar psicológico destas mulheres (Jonathan, 2005).

Em seu conjunto, estudos desenvolvidos com brasileiras que exercem funções de liderança no espaço público sugerem que elas valorizam tanto a realização profissional, quanto a maternidade, o relacionamento afetivo estável com um par, e o tempo dedicado a si mesmas (Jonathan, 2001, 2005; Rocha-Coutinho, 2003). Fica claro que estas mulheres líderes propõem uma convivência mais enriquecedora entre família, trabalho e pessoa, buscando reafirmar e fortalecer os vínculos entre afeto e trabalho, entre produção e reprodução, tal como enfatizado por Codo, Sampaio e Hitami (1993).

Porém, a valorização dos diversos papéis pode variar em função de diferentes circunstâncias e do momento vivenciado. Neste sentido, Hewlett (2003) observa que dentre as mulheres mais bem sucedidas na esfera pública, $49 \%$ completam 40 anos sem terem filhos, indicando que aproximadamente metade deste contingente de mulheres dedicam-se, primordialmente, à carreira para depois constituírem uma família. Nestas circunstâncias, é possível que deixem para um segundo plano o relacionamento amoroso, que termina se configurando como um fator de escolha de momento. Por outro lado, no contexto brasileiro, verifica-se que aproximadamente $66 \%$ das empreendedoras constituem primeiro a família e só depois realizam o projeto do negócio próprio (Jonathan, 2001), o que revela uma forma alternativa de lidar com o dilema família-trabalho.

A questão da multiplicidade dos papéis femininos, acima analisada, evidencia a importância do exercício de fazer escolhas sem pressões e cobranças. Trata-se de uma necessidade a ser reconhecida pelas organizações e pela sociedade como um todo, a qual, segundo Halpern (2004), precisa encontrar novos e mais adequados modelos de articulação entre o mundo do trabalho e a realidade atual da vida familiar.

O presente trabalho tem o propósito de aprofundar a discussão e a compreensão da experiência das empreendedoras brasileiras em relação à multiplicidade de papéis sociais femininos, focalizando o seu universo simbólico. Que dilemas as empreendedoras vivenciam? De que forma elas lidam com demandas conflitantes? Como articulam os espaços profissional, familiar e pessoal? Essas são as questões centrais para as quais se buscam respostas em uma pesquisa de campo.

\section{Método}

O objetivo de expor a compreensão que as próprias mulheres tinham de suas experiências como empreendedoras norteou a estruturação da abordagem metodológica do estudo aqui relatado.

Uma amostra de conveniência foi constituída por 49 empreendedoras cariocas, donas de negócios em diversos setores da economia. A participação no estudo foi condicionada pelos seguintes critérios: possuir uma empresa não franqueada atuando no mercado há pelo menos um ano; ter significativa participação acionária no empreendimento; estar ativamente envolvida no dia-a-dia da empresa; desempenhar uma função de liderança administrativa e/ou técnica.

O primeiro contato com as participantes foi realizado por telefone ou pessoalmente. Convidadas a participar de uma pesquisa sobre a experiência das empreendedoras brasileiras, as donas de negócios próprios foram muito receptivas, concordando em conceder uma entrevista em suas empresas.

Após o preenchimento de um questionário com dados descritivos pessoais e da empresa, realizaram-se entre- 
vistas semi-estruturadas, fundamentadas em um roteiro com 13 questões abertas e com a duração de aproximadamente 45 minutos. Conflitos e formas de enfrentamento, foco principal dos dados relatados no presente artigo, foi um dos cinco temas abordados na entrevista. As demais temáticas abordadas foram: trajetória e motivação; fontes de satisfação e de insatisfação; medos e preocupações; e conseqüências de ser empreendedora.

As entrevistas foram gravadas com o consentimento das participantes e em seguida transcritas. Visando captar o universo de significações contidas nos discursos das empreendedoras, as transcrições foram submetidas a uma análise de conteúdo (Bardin, 1979), cuja metodologia contemplou tanto um exame transversal (entre participantes) quanto um exame vertical (de cada participante) dos depoimentos. A seção seguinte apresenta o material recorrente que emergiu desta análise e que foi organizado em categorias dentro de cada um dos temas de análise, ou seja, tipos de conflito vividos pelas empreendedoras e formas de ação usadas para enfrentá-los.

\section{Resultados}

A seguir, inicialmente são descritos os dados obtidos nos questionários; os demais resultados relatados decorrem da análise qualitativa das entrevistas.

Os resultados evidenciaram que as empreendedoras tinham em média 46,5 anos, sendo 68,7\% casadas, 18,7\% solteiras e $12,5 \%$ separadas. Coerente com sua idade e seu estado conjugal, $83,7 \%$ possuíam filhos (média de 2,1 filhos), dentre os quais 65,9\% tinham mais de 18 anos, $18,2 \%$ entre 12 e 18 anos, e 15,9\% tinham menos de 12 anos. Quase todas as empreendedoras contavam com ajuda nos cuidados com o lar, sendo que $64,4 \%$ possuíam empregados e $28,8 \%$ tinham o apoio de familiares.

Foi observado, também, que a maioria $(61,2 \%)$ das empreendedoras possuía o nível superior completo, e que elas comandavam microempresas (média de 8,9 funcionários) bem estabelecidas no mercado (média de 9,7 anos), na área de serviços $(55,36 \%)$, do comércio $(33,93 \%)$ e da indústria $(10,71 \%)$.

O profundo envolvimento das participantes com suas empresas foi evidenciado tanto por sua significativa participação acionária no empreendimento (média de 63,2\% de participação), quanto pelo elevado número de horas dedicadas às empresas (média de 10,4 horas diárias). Os resultados mostraram, ainda, que 46,9\% das empreendedoras gostariam de manter o número de horas dedicadas, ao passo que $40,8 \%$ gostariam de dedicar menos horas e $12,2 \%$ desejavam aumentar sua dedicação diária aos negócios.
Indagadas se vivenciavam situações de conflito, as empreendedoras espontaneamente reportaram situações conflituosas de diferentes naturezas, a saber: conflitos no espaço do trabalho; conflitos entre as demandas da família e aquelas relativas ao trabalho; conflitos entre necessidades do trabalho e necessidades de ordem pessoal. Complementarmente, muitas empreendedoras relataram não experimentarem quaisquer conflitos, enfatizando que adoravam o que faziam e que o trabalho favorecia o seu crescimento bem como sua percepção de auto-realização. A seguir, as categorias de conflitos observadas são ilustradas com trechos das falas das empreendedoras.

\section{Conflitos no Trabalho}

Esta categoria de impasse foi a mais freqüentemente mencionada e, como esclarecem as empreendedoras, envolveu pessoas ou aspectos financeiros:

“...às vezes com o sócio quando as opiniões se divergem, e aí se criam conflitos” (51 anos, atuação em serviços).

“...problemas com os funcionários, porque o nível das pessoas, a educação geral das pessoas nesse país é muito ruim... você simplesmente não fala a mesma língua das pessoas...” (44 anos, atuação no comércio).

“Às vezes as pessoas entram aqui na loja e acham que... podem tratar os objetos em exposição como se fosse uma coisa menor, eventualmente quebrar, sujar, mexer. Aí é a coisa de lidar com o público...” (56 anos, atuação na indústria).

"Então, o que me causa medo e conflito é crescer e ter necessidade de pegar dinheiro de banco, crescer com dinheiro de banco, eu nunca peguei dinheiro emprestado de banco..." (38 anos, atuação em serviços).

\section{Conflitos Família x Trabalho}

Embora não fossem os mais freqüentemente mencionados, os conflitos família $\mathrm{x}$ trabalho foram considerados os mais problemáticos e difíceis de equacionar. Neste contexto, o sentimento de culpa que ocasionalmente emergiu tendia a se vincular a dificuldades já superadas, sendo a culpa remetida ao passado:

Agora não tanto [conflito] porque eu me separei, mas quando eu era casada eu tinha muito problema... porque, de início, eu não tinha a estrutura [na empresa] que eu tenho hoje... eu fazia muita coisa... (33 anos, atuação em serviços).

...eu tive que aprender a lidar com as situações. Eu tinha culpa, principalmente com os filhos, de não estar presente; achava que tudo o que faziam errado era porque eu não estava presente. Até o dia que eu percebi que não tem nada a ver comigo, que era com eles... (34 anos, atuação em indústria). 


\section{Conflitos Trabalho x Pessoa}

A incidência desta categoria de dilema foi pequena, sendo o ponto crucial a energia e o tempo dedicados ao negócio face ao que ficava disponível para questões pessoais, como nos dizem as empreendedoras:

"Vivencio situações conflituosas porque eu e minha irmã que somos sócias estamos priorizando a nossa qualidade de vida, só que isso embate com o crescimento da empresa...” (45 anos, atuação no comércio).

“...existe uma coisa que me incomoda muito que é a disponibilidade de tempo para mim, para as minhas coisas, que é pequena..." (48 anos, atuação em serviços).

\section{Estratégias de Enfrentamento}

De forma ampla, as mulheres apresentaram uma postura fortemente assertiva onde arrependimentos tenderam a estar ausentes e o emprego da palavra "conciliar" se fez presente. Ao refletirem diretamente sobre a articulação entre os triplos desafios enfrentados (profissionais, familiares e pessoais), as empreendedoras reconheceram as dificuldades existentes, o que ficou explícito pelo uso dos termos "complicado" e "enroladinho", entre outros similares.

Os dados mostram que, a fim de lidar com as demandas conflitantes, as empreendedoras recorriam, principalmente, a três estratégias de ação: (a) auto-organização do tempo; (b) estabelecimento de parcerias ou cumplicidade; (c) uso de dispositivos de alívio de tensão.

\section{Auto-Organização do Tempo}

No dia-a-dia, diferentes necessidades foram consideradas importantes, exigindo uma atitude pró-ativa e de ordenação das ações, como diz uma das empreendedoras:

...é importante mente sã e corpo são; não tem jeito, você tem que se cuidar e há tempo para isso porque tempo a gente faz; a gente tem que ter tempo para poder fazer de tudo... ninguém cresce se não tiver método e disciplina... (47 anos, atuação no comércio e em serviços).

Diante das diferentes solicitações profissionais, familiares e pessoais, as empreendedoras mostraram que exerciam sua capacidade de administrar. Dessa forma, organizar-se quanto ao tempo disponível, fazer um certo rodízio do foco de atenção, bem como separar os espaços das diferentes atividades foram freqüentemente invocados como formas de enfrentar demandas em conflito, como ilustram, respectivamente, as falas a seguir:

Eu acordo bem cedo, levo o meu filho menor na escola e vou para a ginástica; depois começo no telefone e à tarde venho para a empresa. Daqui busco o do meio no futebol e volto para casa. Cuido do dever dos filhos, vejo se já jantaram. Concilio tudo; tem que dar para conciliar (37 anos, atuação no comércio).
"Pego a manhã e dirijo para minhas atividades, faço terapia e ginástica” (42 anos, atuação em serviços).

A gente tenta separar as situações... dentro do salão eu me dedico ao salão, aos clientes, às pessoas, aos funcionários... quando estou na minha casa, saio daqui, fechei as portas e no caminho estou me desligando daqui, eu vivo a minha família e esqueço daqui... vivo só para eles (40 anos, atuação em serviços).

\section{Parcerias e Cumplicidade}

Face às demandas conflitantes, as empreendedoras também recorreram ao estabelecimento de alianças com familiares e/ou com pessoas ligadas ao trabalho:

\begin{abstract}
...meu marido é muito parceiro... ele chega e já vai adiantando; se ele tiver que fazer um arroz, ele vai fazer...; não deixa tudo nas minhas costas... a gente é muito unido... (47 anos, atuação no comércio e em serviços).

“...Eu até consigo conciliar bem... Tem a [nome da pessoa] que a gente é sócia; a gente divide, então, uma sempre cobrindo a outra..." (34 anos, atuação em serviços).

“...Então nunca teve essa coisa de homem não faz isso, homem não faz aquilo, eventualmente... um sabe fazer melhor do que o outro filho...” (60 anos, atuação no comércio).
\end{abstract}

Observou-se, ainda, que as mulheres utilizavam variados expedientes para diminuir a tensão e, assim, contornar as situações conflitantes. Neste sentido, atividade física, viagens, espiritualidade e psicoterapia foram os principais dispositivos usados, como afirmam, respectivamente, as empreendedoras:

"Faço minha hidroginástica e minha caminhada; tem dias que não dá porque eu tenho que atender o cliente no horário" (48 anos, atuação no comércio).

...procuro equilibrar tudo; ...sou uma pessoa feliz com tudo, mas existem momentos que dá vontade de desistir; ...eu gosto de viajar, viajo com o meu marido ou até sozinha... tem que ter momentos de escape... (34 anos, atuação em serviços).

"Desligando no final de semana e indo à igreja com a família; fazendo orações..." (38 anos, atuação em serviços).

“...tive uma terapia de apoio de família; fizemos porque o trabalho da mulher na época..., isso pesava para a minha geração..." (57 anos, atuação em serviços).

\section{Discussão}

O perfil das empreendedoras e o de seus empreendimentos, aqui descritos, são semelhantes aos revelados em pesquisas sobre o empreendedorismo feminino no Brasil 
(Jonathan, 2001, 2003; Machado, Barros \& Palhano, 2003). As empreendedoras são, em sua maioria, mulheres altamente escolarizadas, de meia-idade, casadas, mães, e possuem microempresas principalmente no setor de serviços.

Destaca-se também o forte compromisso que as empreendedoras têm com os seus empreendimentos, pois não somente possuem uma substancial participação acionária na empresa como também dela se ocupam durante muitas horas diárias. Manter ou, mesmo, aumentar sua grande dedicação diária aos negócios, como é o desejo expresso por muitas empreendedoras, sinaliza que a condução de suas empresas se constitui como um projeto central em suas vidas, possivelmente facilitado pela ajuda, principalmente, de empregados com que contam no cuidar do lar.

O que pensam as empreendedoras acerca das situações conflituosas que vivenciam? Ao contrário das expectativas fundamentadas na visão de que o binômio família-trabalho encerra demandas inconciliáveis em sua natureza, e, portanto, sempre presentes, os conflitos família $\mathrm{x}$ trabalho foram menos freqüentemente mencionados do que os conflitos no próprio contexto do trabalho. A maior ênfase atribuída a estes últimos indica a grande relevância do trabalho na vida das empreendedoras e sinaliza uma mudança nos atuais papéis sociais de gênero, questionando, assim, os mitos relativos à diferença entre os gêneros que permeiam a organização do trabalho e da família (Barnett, 2004).

Os dados sugerem que o dilema família $x$ trabalho não é uma questão enfatizada por muitas empreendedoras que também são mães, possivelmente porque se sentem muito satisfeitas e auto-realizadas no exercício de múltiplos papéis (Cherlin, 2001; Possati \& Dias, 2002). Deve-se ainda levar em consideração o fato da maioria das empreendedoras ser de meia idade e ter os filhos crescidos, o que pode também ter contribuído para diminuir a relevância do dilema em questão.

Porém, não se pode perder de vista que, quando os conflitos família $x$ trabalho são vivenciados, as empreendedoras reconhecem que estes são os mais difíceis de resolver. Assim, se, de um lado, algumas empreendedoras reportam que sentem certa culpa - principalmente em relação aos filhos -, tal como argumentam Rocha-Coutinho (2003) e Jablonski (1996), de outro, a questão da culpa parece ter sido equacionada na medida em que é remetida ao passado. Conclui-se, então, que as empreendedoras tendem a encontrar um meio termo entre família e trabalho (Uchitelle, 2002).

Tomados em conjunto, os dados indicam que a forma de lidar com os dilemas é mais relevante do que sua própria existência. Vale destacar que a postura assertiva das empreendedoras se fundamenta no reconhecimento das dificuldades envolvidas na articulação das demandas profissionais, familiares e pessoais. Elas se sentem desafiadas, arrependimentos tendem a não existir e o desejo de conciliar as múltiplas necessidades é um ideal que perseguem de forma ativa, confirmando dados de Rocha-Coutinho (2003) e de Jonathan (2001), e que freqüentemente conseguem concretizar, fato observado também em outros estudos (Jonathan, 2001, 2005).

No enfrentamento de demandas conflitantes, as empreendedoras adotam, principalmente, três estratégias de ação: a auto-organização do tempo, o estabelecimento de parcerias e o uso de dispositivos de alívio de tensão. Tais estratégias não se excluem mutuamente e, na verdade, possibilitam o êxito no enfrentamento dos dilemas por introduzirem mudanças nos espaços do trabalho, familiar e pessoal.

A auto-organização do tempo é uma estratégia de otimização e envolve três procedimentos: (a) planejar e administrar o tempo disponível, um comportamento vinculado ao desejo expresso por algumas empreendedoras de diminuir as horas de trabalho; (b) alternar o foco da atenção dada às diferentes demandas; (c) separar os espaços das diferentes atividades. Embora se possa compreender que a auto-gestão do tempo seja privilegiada pelas empreendedoras como forma de enfrentar os impasses por ser inerente à função de administrar o seu próprio negócio, trata-se de uma estratégia amplamente utilizada por mulheres, sejam elas mães trabalhadoras americanas (Tiedge, 2004), ou executivas brasileiras (Rocha-Coutinho, 2003).

Já o estabelecimento de parcerias como estratégia de articulação entre as demandas se configura como um recurso que as empreendedoras compartilham com as executivas (Rocha-Coutinho, 2003). No entanto, diferentemente das executivas, as empreendedoras enfatizam não só as alianças com os familiares como também aquelas com as pessoas do espaço do trabalho (sócios e funcionários).

Como visto anteriormente, atividade física, psicoterapia, espiritualidade e viagens constituem uma terceira estratégia que, através do alívio da tensão, possibilita fazer frente às demandas conflitantes. Face a esse dado, pode-se argumentar que esta não é uma estratégia de uso exclusivo das empreendedoras. Entretanto, deve-se reconhecer que, ao utilizá-la, as empreendedoras imprimem, em sua forma de gestão empresarial, a atenção às questões pessoais, transmitindo tais valores aos seus colaboradores.

Ampliando a discussão, os dados do presente estudo expõem questões apontadas por González Rey (2004) como importantes na construção do conhecimento em Psicologia Social, na medida em que eles permitem compreender a produção de sentido das empreendedoras em seu cotidiano, e como tal produção se vincula à integração dos vários espaços de sua vida social. Articulados com a análise dos fundamentos teóricos da Psicologia Social (Khoury, 1999; Gonçalves, 2002), os resultados evidenciam como 
mulheres empreendedoras, implicadas no seu contexto sócio-cultural concreto e contraditório, desenvolvem suas percepções, seus sentimentos e pensamentos através da atividade, atividade esta que se explicita em diferentes estratégias de enfrentamento das contradições. No contexto de uma perspectiva sócio-histórica, pode-se argumentar, também, que as mulheres, no desenvolvimento histórico de suas experiências como empreendedoras, constroem o seu universo construindo-se a si mesmas, num movimento dialético (Bock, 2002).

Por outro lado, conhecer a produção de sentido dos sujeitos é condição essencial para uma prática profissional em Psicologia Social. É importante, pois, ampliar olhares e escutas sobre o cotidiano que entrelaça a empreendedora, sua família e seu trabalho. Trazer à luz diferentes formas utilizadas pelas empreendedoras para lidarem com demandas em conflito fornece subsídios para tal prática, um fazer concebido como uma intervenção que visa a transformação ou reestruturação de como as pessoas configuram o seu cotidiano (Bock, 2002). Neste sentido, são interessantes os dados que sugerem que, ao invés de serem dominadas pela culpa, sinal de um não ajustamento à ordem social, as empreendedoras superam as contradições inerentes aos conflitos vivenciados, transformando a própria ordem social e a si mesmas.

\section{Considerações Finais}

Sem dúvida, o exercício do empreendedorismo feminino promove o confronto de diversos conflitos e as empreendedoras apresentam grande variedade de estratégias de ação na tentativa de encontrar um equilíbrio entre diferentes demandas. No entanto, tecer os fios das contradições associadas à multiplicidade de papéis é um processo e não um estado, requerendo das empreendedoras constantes negociações face às circunstâncias que se modificam.

A trajetória das empreendedoras é marcada pela busca de auto-realização. Neste contexto, as mulheres sentem mais satisfação do que culpa ao construírem um projeto de vida centralizado no exercício do empreendedorismo ao qual se dedicam com afinco e com o qual estão profundamente comprometidas.

A análise das experiências das empreendedoras evidencia que elas inovam incessantemente, criando arranjos alternativos para os conflitos que as desafiam, o que termina produzindo transformações no seu universo, tanto no âmbito do trabalho, quanto nos âmbitos familiar e pessoal. Porém, como anteriormente argumentado, a re-configuração dos espaços do trabalho e da família e dos papéis sociais a eles vinculados não é uma problemática a ser equacionada unicamente pelas empreendedoras: a harmonia do público com o privado é uma ampla questão social de responsabilidade de todos, independente do gênero e do tipo de ocupação no mercado de trabalho.
Por fim, conclui-se que a atualização do potencial econômico e de inovação do empreendedorismo feminino praticado no Brasil repousa na melhor compreensão das questões psicológicas e sociais que envolvem as empreendedoras. O presente artigo propõe ser uma contribuição nesta direção.

\section{Referências}

Bardin, L. (1979). Análise de conteúdo. Lisboa, Portugal: Edições 70.

Barnett, R. C. (2004). Preface: Women and work: Where are we, where did we come from, and where are we going? Journal of Social Issues, 60(4), 667-674.

Bock, A. M. B. (2002). A Psicologia sócio-histórica: Uma perspectiva crítica em psicologia. In A. M. B. Bock, M. G. M. Gonçalves \& O. Furtado (Eds.), Psicologia sócio-histórica: Uma perspectiva crítica em psicologia (2. ed., pp. 15-35). São Paulo, SP: Cortez.

Cherlin, A. J. (2001). Public and private families: An introduction (3nd ed.). New York: Mc Graw Hill.

Codo, W., Sampaio, J. J. C., \& Hitomi, A. H. (1993). Indivíduo, trabalho e sofrimento: Uma abordagem interdisciplinar. Petrópolis, RJ: Vozes.

Cuddy, A. J. C., Fiske, S. T., \& Glick, P. (2004). When professionals become mothers, warmth doesn't cut ice. Journal of Social Issues, 60(4), 701-718.

Global Entrepreneurship Monitor (2003). Relatório Global de Empreendedorismo no Brasil-2003. Curitiba, PR: Instituto Brasileiro de Qualidade e Produtividade no Paraná.

Gonçalves, M. G. M. (2002). A psicologia como ciência do sujeito e da subjetividade: A historicidade como noção básica. In A. M. B. Bock, M. G. M. Gonçalves \& O. Furtado (Eds.), Psicologia sócio-histórica: Uma perspectiva crítica em psicologia (2. ed., pp. 37-52). São Paulo, SP: Cortez.

González Rey, F. (2004). O social na Psicologia Social e a Psicologia Social: A emergência do sujeito. Petrópolis, RJ: Vozes.

Halpern, D. (2004). Making it work: Recommendations for policies on working families. Monitor on Psychology, 35(3), 5.

Hewlett, A. S. (2003). Em busca do tempo perdido. Revista Exame/ Você S/A, 57, 70-73.

Hisrich, R. D., \& Peters, M. P. (2002). Entrepreneurship (5nd ed.). Boston: Irwin/McGraw Hill.

Jablonski, B. (1996). Papéis conjugais: Conflito e transição. In T. Féres-Carneiro (Ed.), Relação amorosa, casamento, separação e terapia de casal: Vol. 1. Coletâneas da ANPEPP (pp. 113123). Rio de Janeiro, RJ: Xenon.

Jonathan, E. G. (2001). Mulheres empreendedoras: Quebrando alguns tabus. In Anais do III Encontro Nacional de Empreendedorismo-ENENPRE [CD-ROM]. Florianópolis, SC: Editora da Universidade Federal de Santa Catarina.

Jonathan, E. G. (2003). Empreendedorismo feminino no setor tecnológico brasileiro: Dificuldades e tendências. In Anais EGEPE $3^{\circ}$ Encontro de Empreendedorismo e Gestão de Pequenas Empresas (pp. 41-53). Brasília, DF: Editora da Universidade de Brasília; Curitiba, PR: Editora da Universidade Estadual de Maringá/Editora da Universidade Estadual de Londrina.

Jonathan, E. G. (2005). Mulheres empreendedoras: Medos, conquistas e qualidade de vida. Psicologia em Estudo, Maringá, 10(3), 373-382.

Khoury, H. (1999). Fundamentos teórico-metodológicos para uma Psicologia Social científica. In E. M. Bonfim (Ed.), Psicologia 
Jonathan, E.G.; Silva, T.M.R. "Empreendedorismo Feminino: tecendo a trama de demandas conflitantes"

Social: Horizontes contemporâneos (pp. 31-41). Belo Horizonte, MG: ABRAPSO.

Macêdo, K. B., Caixeta, C. M. M., Guimarães, D. C., Macedo, G. N. S., \& Hernandez, J. C. (2004). O processo sucessório em organizações familiares e a exclusão da mulher. Psicologia \& Sociedade, 16(3), 69-81.

Machado, H. P. V., Barros, G. V., \& Palhano, D. Y. M. (2003). Conhecendo a empreendedora norte-paranaense: Perfil, porte das empresas e dificuldades de gerenciamento. In Anais EGEPE - $3^{\circ}$ Encontro de Empreendedorismo e Gestão de Pequenas Empresa (pp. 171-197). Brasília, DF: Editora da Universidade de Brasília; Curitiba, PR: Editora da Universidade Estadual de Maringá/Editora da Universidade Estadual de Londrina.

McClelland, D. C. (1961). The achieving society. Princeton, NJ: Van Nostrand.

Mizrahi, B. G. (2004). A relação pais e filhos hoje: A parentalidade $e$ as transformações no mundo do trabalho. Rio de Janeiro, RJ: Editora da Pontifícia Universidade Católica do Rio de Janeiro; São Paulo: Edições Loyola.

Moore, D. P., \& Buttner, E. H. (1997). Women entrepreneurs: Moving beyond the glass ceiling. Thousand Oaks, CA: Sage.

Morrison, A., White, R., \& Van Velsor, E. (1987). Breaking the glass ceiling: Can women reach the top of America's largest corporations? Reading, MA: Addison-Wesley.

Possati, I. C., \& Dias, M. R. (2002). Multiplicidade de papéis da mulher e seus efeitos para o bem-estar psicológico. Psicologia: Reflexão e Crítica, 15(2), 293-301.

Rocha-Coutinho, M.L. (2003). Quando o executivo é uma "dama": A mulher, a carreira e as relações familiares. In T. Feres-Carneiro (Ed.), Família e casal: Arranjos e demandas contemporâneas (pp. 57-77). Rio de Janeiro, RJ: Editora da Pontifícia Universidade Católica do Rio de Janeiro; São Paulo: Edições Loyola.

Shindhutte, M., Morris, M., \& Brennan, C. (2001). Female entrepreneurs and their children: Implications for family life, career aspirations and entrepreneurial perceptions. In Frontiers of Entrepreneurship Research. Wellesley, MA: Center for Entrepreneurial Studies/Babson College. Retirado em 02 set. 2003, de http:// www.babson.edu/entrep/fer/Babson2001/IV/IVF/IVF/iv-f.htm.
Tiedge, L. B. (2004). Processes of change in work/home incompatibilities: Employed mothers 1986-1999. Journal of Social Issues, 60(4), 787-800.

Uchitelle, L. (2002, July 6). A middle way: More moms find a balance for job and family. International Herald Tribune.

Vandewater, E. A., Ostrover, J. M., \& Stewart, A. J. (1997). Predicting women's well-being in midlife: The importance of personality development and social role involvements. Journal of Personality and Social Psychology, 72(5), 1147-1160.

Weeks, J. R., \& Seiler, D. (2001). Women's entrepreneurship in Latin America: An exploration of current knowledge. Washington, DC: Inter-American Development Bank.

Eva G. Jonathan é psicóloga e mestre em Psicologia pela Pontifícia Universidade Católica do Rio de Janeiro - PUC - Rio. Docente do Departamento de Psicologia, PUC - Rio. Pesquisadora Associada do Núcleo de Estudos e Pesquisas do Instituto Gênesis, PUC - Rio. Endereço para correspondência: Rua Marquês de São Vicente, 225 - CEP 22453-900 Rio de Janeiro, RJ. evajonat@psi.puc-rio.br

Taissa M. R. da Silva é psicóloga pela PUC - Rio. Formanda em Psicoterapia Gestáltica, Centro de Gestalt-terapia Sandra Salomão. taissamoreira@yahoo.com.br

\section{Empreendedorismo Feminino: tecendo a trama de demandas conflitantes}

Eva G. Jonathan e Taissa M. R. da Silva

Recebido: 06/1/2006

$1^{\text {a }}$ revisão: 25/09/2006

$2^{\text {a }}$ revisão: $19 / 10 / 2006$

Aceite final: 28/11/2006 